\title{
Foreign countries, foreign customs: an analysis of short-distance mobility of new immigrants in the Rhine-Main region in Germany
}

Isabella Geis ${ }^{1,2}$ (D)

\begin{abstract}
Mobility is an important driver of social integration. Against this background, the years since 2014 challenged cities and municipalities in Europe when a large number of immigrating refugees came to Europe and had to be integrated into society. Federal, regional, and local politics had to find strategies to overcome these difficulties without detailed understanding of the needs. Research has shown that mobility behaviour of recently settled immigrants significantly differs from locals due to language barriers or different mobility cultures, for example. However, little is known about the details of difference and how supportive measures actually affect their mobility behaviour. Using the example of asylum applicants from the Middle East and Africa in the metropolitan region of Frankfurt Rhine-Main in Germany, this paper analyses mobility for immigrants from the demand and supply sides. It brings together mobility demand and local and political efforts to satisfy this demand. Data were collected in focus groups, a survey among relevant public organisations, and a survey among immigrants. Results show that there is a need for action, as current measures, such as information on public transport or bicycle courses for immigrants, are not as effective as expected. Concurrently, data reveal that public administration and voluntary organisations have reached their limits and cannot intensify mobility measures for immigrants. Based on these findings, recommendations for public administration, voluntary workers, transport planners, and policy makers are derived that help to improve the situation of immigrant mobility.
\end{abstract}

Keywords: Mobility behaviour, Transport planning, Mobility provision

\section{Introduction and background}

Mobility is an important component of social participation and integration. It allows access to employment, education, and social networks - in total, to modern life and societal opportunities [1-3]. Digitalisation can have a substituting effect: Internet and mobile devices allow home office solutions for a number of jobs. Education can increasingly take place with online courses and seminars. Emails, smartphones, sophisticated video conference systems, and messenger services have become essential elements of communication. They enable contact bridging long distances with little or no time lag.

Correspondence: isabella.geis@googlemail.com

${ }^{1}$ Fraunhofer-Institute for Material Flow IML, Bessie-Coleman-Straße 7, 60549

Frankfurt/Main, Germany

${ }^{2}$ Present Address: Q_PERIOR, Baseler Straße 10 60, Frankfurt/Main, Germany
Still, digitalisation does not succeed in reducing the need for mobility. It remains with its central position in people's everyday life. Moreover, constant growth in the annual passenger transport volume can be recorded. The car is by far the most important means of transport in industrialised countries [4].

At the same time, mobility is a learned and highly habitualised behaviour, which relies on routines and repetitive actions [5-7]. Therefore, already little differences, for example another ticketing system, other rules for using public transport or language barriers, challenge this learned behaviour and its routines. Hence, mobility in a foreign mobility system is especially difficult as the learned routines no longer work. The challenge for mobility providers is to make mobility available to all users taking into account individual mobility routines. 
Against this background, the years since 2014 challenged many cities and municipalities in Europe, when a large number of immigrating refugees came to Europe. The situation in countries of the Middle East but also on the African continent drove many people towards Europe (e.g. political instability, conflicts and wars, drought or poor living conditions). Countries, administrations, and cities suddenly were confronted with questions of integration on a very large scale. Quite suddenly, public administrations had to handle additional demand for public services. Housing and education were not prepared for this rapid rise in demand. Among these challenges, mobility seems to be a subtopic. Yet besides overcoming language barriers, mobility is a central aspect of integration, as it allows immigrants to participate in integration and language courses, to find employment, and, above all, to expand their social network outside of their direct surrounding. As refugees were often accommodated in groups with other refugees, the risk of isolation and little enclaves exists. Research, however, has shown that especially immigrants living in isolated areas tend to be less mobile and have fewer networks outside their direct environment $[2,8]$. This, in turn, causes higher risks of unemployment and social exclusion [3]. This already shows that mobility has a highly social component that has to be considered when planning mobility. It is thus essential to ensure that mobility systems are accessible and understandable for immigrants, even when they have only been living for a short period in the country. However, mobility provision is costly and resource-consuming. Additional offers are therefore not only a question of good will. Nevertheless, in Germany and other countries, a list of short-term measures to enable mobility for new immigrants has been set up.

The distribution of immigrants differs over Germany. The Rhine-Main region has become the fifth strongest region for immigrants. In 2015 alone, 75,000 refugees arrived in the metropolitan region [9]. Generally, the share of immigrants strongly differs between $7 \%$ in Vogelsberg, in the northern part of the region, to almost $35 \%$ in Offenbach, which is located in the heart of the metropolitan region. However, different groups of immigrants have to be differentiated: (1) people with immigrant background, which covers all people who either have immigrated themselves or have at least an immigrated parent, and (2) immigrants, which describes people who have immigrated themselves. For the second group, motivation can be very different, such as employment, political instability due to wars, poverty, social reasons, education, and many more. Among the group of immigrants, refugees and asylum-seeking people are a sub-group that has immigrated from necessity due to war or political or religious persecution, for example.
This group of immigrants has a non-European background and has recently come from the Middle East or Africa. Little is known about these immigrants. Neither socio-demographic details nor facts about their mobility behaviour or mobility background are known. This is as before 2014 this group existed but did not stand out in terms of size. Many assumptions circulate about how this group of immigrants is mobile and uses the mobility system. What is clear is that there are immense language barriers orally and in writing and that this group is characterised by a high rate of illiteracy. Learning and integration therefore have special challenges to overcome.

As this group has received so little attention in research up to now but nowadays plays a significant part in German and European society, this study aims at providing a profound understanding of the mobility behaviour of recently settled immigrants. The results of this paper are based on a study conducted in the metropolitan region of Frankfurt Rhine-Main in the centre of Germany. The study focused on recently settled immigrants from the Middle East and the African continent, usually refugees and asylum-seeking people, and service providers that offer support to these people when trying to start life in the metropolitan region (e.g. municipalities, public transport providers, or voluntary workers). Therefore, in this paper, a twofold perspective is taken to answer the question of how short-distance mobility of recently settled immigrants can be supported: First, the paper sheds light on the question of what marks short-distance mobility behaviour of immigrants from the Middle East and African countries in Frankfurt Rhine-Main. Second, the author analyses current mobility offers and challenges for public transport providers or municipalities in the integration of this immigrant group in our mobility system. The demand and supply sides are compared, and recommendations for policy makers, transport planners, and further groups are developed. Data were collected in focus groups, a survey among relevant public organisations, and a survey among immigrants. For reasons of readability, the term immigrant is used in this paper without further specification. However, in this paper it will be used to refer only to those who have recently settled in Germany (not more than two years) and are from the Middle East or the African continent.

The rest of the article is structured as follows. Section 2 presents a literature review to highlight the most relevant research contributions in this research field. Section 3 explains the underlying methodology as well as the challenges that have to be overcome for this research. The research-relevant characteristics of the target group are explained, and the study area is introduced. Section 4 shows the results of the data collection. The analysis is divided into supply and demand sides. Section 5 
discusses the empirical results, highlights gaps between demand and supply, and formulates recommendations for the involved stakeholders on how to facilitate mobility and mobility provision. Herewith, the author addresses public administration, voluntary workers, and policy makers and points out organisational and planning aspects to be considered.

\section{Literature review}

Determinants of travel behaviour are an important topic in research [5]. Research has shown that demographic factors, such as gender or age, have an effect on how people travel [10-13]. Furthermore, different mobility behaviours can be explained by different cultures and the geographical environment. Bühler [14], for instance, argues that Germans have a higher probability to use public transport compared to Americans [14]. Research shows an increasing interest in mobility behaviour of immigrants. Most studies on the mobility behaviour of immigrants have been conducted among immigrants in America. Blumenberg [15], for example, argues that immigrant mobility behaviour significantly changes local mobility behaviour. The author suggests that the increasing number of immigrants changes the demographic structure of daily travellers and specifically increases the demand for mobility [15]. As other authors have already shown that demographic factors influence modal choice, these results indicate that transport policy has to be rethought if immigrants significantly change travellers' characteristics.

Additionally, Tal and Handy [16] conducted a more differentiated analysis of immigrants in America. They analysed the relation between mobility behaviour and immigrant status. Based on data of the National Household Transportation Survey, the influence of the place of birth and the year of immigration to the United States was examined. The central result was that the year of arrival plays a role for immigrants who have recently settled in the US but loses importance the longer the immigrants have already been in the US. The place of birth had a rather diffuse effect. Some countries of origin had an influence, whereas others did not [16]. An analysis by $\mathrm{Hu}$ [17] showed similar results for Asian immigrants. It was pointed out that recently settled Asian immigrants have a significantly different mobility behaviour to Asian immigrants who have already been in the country for a while [17].

Other studies focus on a specific immigrant group. An article from 2016, for example, examined the mobility of Chinese immigrants in New York City. The article suggests that Chinese immigrants in Queens are relatively immobile as they experience a number of structural barriers, such as racial discrimination, language barriers, or economic restrictions. It was pointed out that accessibility to transport is not enough to solve these barriers or to prevent immigrants from social exclusion. It was emphasised that integration has to be a holistic approach that integrates transport policy, labour policy, and social integration measures [18]. In general, research agrees that a lack of mobility leads to enclaves, social exclusion, and reduced job opportunities. A negative impact on the integration of the immigrants is predicted $[2,19]$.

Besides analysing the mobility demand of immigrants, mobility provision for immigrants is a relevant topic. Interestingly, up to now, little research has focused on this topic. One article, however, identified strategies to address mobility needs of immigrants in California. Five approaches were developed: (1) improvement of transit in public transport, (2) safer and more accessible car travel, (3) improvements for pedestrians, (4) improvements for bicyclists, and (5) innovations in land use patterns for a better integration with transport [20].

Some studies have analysed the neighbourhood effects among immigrants. Research has found that immigrants have a higher probability to carpool if they live in immigrant neighbourhoods than non-immigrants in non-immigrant neighbourhoods [21]. Based on a geocoded dataset, Smart [22] found that immigrants in the US use carpooling, walking, bicycling, and transit significantly more than non-immigrants. The author pointed out that, especially for shopping, immigrants tend to use short-distance mobility by bicycle or foot. An article from 2014 also emphasised the importance of carpooling for immigrants. The authors stated that immigrants tend to be in strong ethnic-related networks, which increases their probability of finding carpooling partners [21]. Most of the research has been conducted in America, which is a strong immigrant nation. For Europe, there exists almost no research on immigrant mobility. The United Kingdom and the Netherlands, however, have received attention [23, 24]. Also for the city of Offenbach am Main in Germany, differences in mobility behaviour of immigrants have been analysed [25]. It is striking that the European studies mostly do not differentiate between people with immigrant background and recently settled immigrants. Germany, for instance, has a high share of people with immigrant background whose parents already immigrated to Germany (e.g. from Italy or Turkey). Their children were already mostly born in Germany. However, recently settled immigrants receive little attention and pose challenges for public administration. Yet, with the strong immigrant years of 2015 and 2016, this became an important and relevant research topic. This paper starts filling this research gap.

\section{Methodology and data collection}

\subsection{The target group}

The research of this paper focuses on immigrants with a refugee background. Labour immigrants, students, etc. 
are excluded from this research. This brings a number of challenges that have to be considered when designing the methodological approach. As the target group comes from many different countries, it is not in the scope and financial resources of this research to provide translation of questionnaires in all languages. The target group is non-native speaking in English or German. Moreover, it must be expected that the target group has only basic knowledge of English or German and can articulate itself with difficulty. Therefore, language barriers are expected. Furthermore, it must be presumed that a significant proportion of the potential respondents is illiterate, which means that even if German or English is understood, it cannot be guaranteed that a questionnaire can be read. Additionally, it must be assumed that relevant questions are not answered honestly, such as age or home country, as the respondents do not trust or understand the concept of anonymity and as they are afraid that an honest answer would cause them disadvantages regarding residence permission or financial support. Therefore, questions have to find balance between being sufficiently unspecific for triggering honest answers and specific enough for data analysis and interpretation. Finally, refugees interact in relatively closed groups due to language barriers or isolated housing, for example. This means that gatekeepers are needed to access suitable research participants.

\subsection{The study area}

As a study area for the research project, the metropolitan region of Frankfurt Rhine-Main was chosen. The study area is visually presented in Fig. 1. It covers an area of around $15,000 \mathrm{~km}^{2}$ with around 5.7 million inhabitants. It consists of seven district-free towns and 18 districts. [26]. An overview of the region is given in Fig. 1. The region is located in the centre of Germany and extends over three federal states (Hesse, Rhineland-Palatinate, and Bavaria). The highest growth for inhabitants is in the cities of Frankfurt, Offenbach, and Darmstadt, whereas other regions are marked by declining inhabitant numbers. Frankfurt Rhine-Main has an average share of foreigners of $16 \%$. The district of Vogelsberg (a very peripheral area with relatively low rents: around 5 Euros per square meter [27]) is marked by the lowest proportion with around $6.5 \%$, whereas Offenbach (as a central and urban area) has the highest proportion of foreigners with around 34\% [28]. In 2015, applications for asylum reached a maximum in Germany and in the metropolitan region. In Hesse alone, 75,000 people applied for asylum in 2015. Already in 2016, the number of applications decreased to 20,500 and fell by another half in 2017. Syria, Afghanistan, and Iraq were the most common countries of origin in 2015. In 2017, the relation changed slightly. Whereas only 600 asylum applications came from Turkey in 2015, 1366 came in 2017, and Turkey became the second most common country of origin after Syria [9].

Frankfurt Rhine-Main generates 250 billion Euros of GDP yearly [26]. It is therefore a significant economic driver in Germany and one of the most important locations for employment. The area is characterised by its strong finance and investment industry (as the seat of the European Central Bank) as well as logistics (e.g. with Frankfurt Airport as the fourth largest airport in Europe [29]). This also makes the area an important transportation hub for the whole of Europe with attractive living conditions. However, this economic prosperity leads to a higher price level. The square meter price for an apartment for rent in Frankfurt is, for instance, 17 Euros, whereas the average in Hesse is 12 Euros and in Germany 9 Euros [30]). Urban areas in particular are characterised by high housing prices. Frankfurt has become the second most expensive German city in terms of housing prices (after Munich). The cities of Mainz, Darmstadt, and Wiesbaden are also among the top 10 [31]. Yet, prices strongly differ per district in the metropolitan region. The more rural a region is, the lower the housing prices are (see e.g. Frankfurt as an urban area with 17 Euros and Schmitten/Hochtaunus as a peripheral are with 8 Euros [30]). The local connection to the general transport infrastructure, such as rail connection and suburban railway, buses, or distance to the airport, strongly influences housing prices [32]. Consequently, it becomes more and more attractive to live in the outer areas, given that mobility does not depend on local public transport and people can be mobile by car. Therefore, a higher share of car ownership can be noticed for regions outside the urban areas [33, 34].

These facts strongly challenge housing for refugees. On the one hand, in 2015 and 2016 municipalities quickly needed large housing areas. Space in urban areas is usually rare and, above all, expensive. On the other hand, accommodations in more rural areas often lack connections with public transport, and being mobile with one's own car is no option for this group. It is a question of including this group and impeding the development of enclaves.

\subsection{The methodological approaches}

An explorative approach was chosen for this paper. Data were collected in the research project 'Short-distance mobility of new immigrants as part of a successful integration strategy: A needs analysis for the Rhine-Main area' [35]. The project aimed at an analysis and comparison of the mobility demand of new immigrants and the mobility supply from the perspective of cities, municipalities, and public transport providers. 


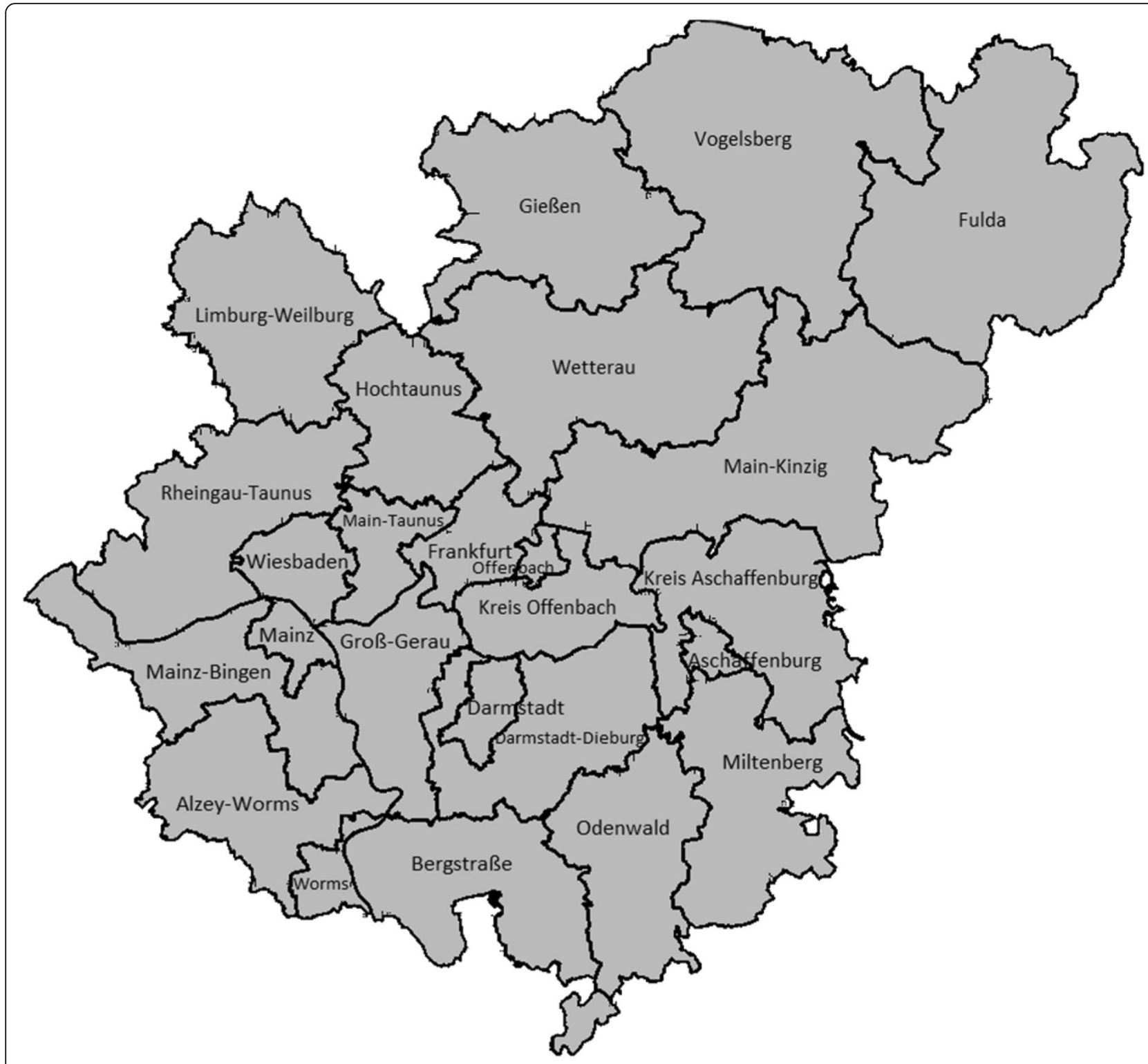

Fig. 1 The study area (designed with OpenStreetMap)

This paper is based on three data collections. First, for the supply side perspective, three focus groups with each between 10 and 12 participants were conducted. Each focus group was dedicated to another topic. Participants in the focus group were representatives of municipalities; the local public transport, especially transport planners; and professional and voluntary integration workers. Participants had to have experience in the provision and planning of mobility, traffic education, or the integration of new immigrants. Participants were invited from the Rhine-Main area to make sure they were familiar with the local conditions and the specific challenges of the region. All focus groups were accompanied by a partially structured guideline. Focus group 1 took place in April
2017. It focused on current measures of supporting short-distance mobility. It covered measures, ratings of acceptance among the immigrants, and organisational aspects of planning mobility for new immigrants. The second focus group was conducted in May 2017 and covered implicit knowledge of the mobility culture, challenges, and barriers to the mobility demand. In August 2017, the third focus group was conducted. Solutions for municipalities and public transport providers were developed that help to provide demand-based and efficient mobility to new immigrants.

Second, the focus groups were complemented with a questionnaire for municipalities and public transport providers. Questions mainly covered the discussion in 
the focus groups to receive an additional and larger-scale picture. The questionnaire was sent to respective institutions of the region via email. Interested institutions filled out the document and sent it back via mail, email, or fax. The survey resulted in 41 respondents and consolidated hypotheses built in the focus group but also allowed for new hypotheses.

Third, data on the demand side (i.e. the immigrants' perspective) were collected with a paper-and-pencil survey among new immigrants (in English and German). As the questionnaire was designed for people of different nationalities with little or no German skills, it was designed to be bilingual. Due to cost restriction, a translation in other languages was not possible. The target group of the survey was new immigrants with a non-European background. Labour immigrants, exchange students, and immigrants with an above-average professional level or education were not analysed in the study. The survey focused on refugees and immigrants with low educational background. Data collection was conducted from April 2017 to August 2017.

\subsection{Survey design}

The survey among immigrants forms an essential part of the data collection. However, several difficulties had to be considered. The target group was diverse in education, language, and reading skills. Due to restricted financial resources, the survey was designed for people with at least basic German or English skills. The language was designed to be as basic as possible, and the questionnaire was accompanied with pictures and signs to facilitate understanding. A first draft of the questionnaire was pretested with representatives of the target group. The pre-test showed that the language had to be further simplified, and the process of filling out a questionnaire had to be explained first. Therefore, instructions for how to fill out a questionnaire were developed. The questionnaire contained questions on the modal split for daily mobility covering car, taxi, public transport, bike, and walking. For each mode, questions were asked on usage frequency, reasons for and against the usage of the mode, and trip purpose.

The respondent was led through the questionnaire mode by mode and always with the same questions per mode to facilitate understanding as far as possible. Furthermore, each block of questions was complemented with mode-specific questions, such as driving licence, car/bike ownership, and distance to the next public transport station. A final block of questions was dedicated to the knowledge of and experience with local mobility offers: subsidisation of public transport tickets, biking lessons, workshops for broken bicycles, information material on local mobility offers, and safety trainings for traffic. Finally, the respondents were asked how well they think mobility in their region fits their needs and how satisfied they are with their daily mobility. The questionnaire was closed with questions on socio-demographics, including gender, age, origin, and year of arrival in Germany. When asking for the country of origin, regions were asked for, such as Eastern Europe, Near East, Northern Africa, etc., as the pre-test showed that specific country origins are not or are incorrectly answered. In the case of age, a range was asked to reduce the risk of deliberately wrong answers. All questions were designed as closed questions. Furthermore, each respondent was accompanied by a trained interviewer who helped with problems of understanding or read out the questions. This was necessary, as most of the respondents had limited or no reading skills.

Participants in the survey were acquired in cooperation with local organisations and institutions that had the role of gatekeepers. The organisations allowed access to waiting rooms during the immigrant consultation hours in social welfare offices, integration courses, or shared accommodations. In all cases, interviewers were on-site to be able to support participants when having language or reading barriers.

\section{Results}

\subsection{Supporting mobility for recently settled immigrants}

\subsubsection{Focus groups and complementary survey sample}

The analysis of measures in the metropolitan region for the mobility of recently settled immigrants is based on the three focus groups and a follow-up survey among relevant institutions and districts. Focus group 1 ('current supporting measures') consisted of 12 representatives from public transport, local transport planners, regional municipalities, regional stakeholders for mobility, and voluntary workers. For focus group 2 ('daily mobility of recently settled immigrants'), seven participants joined. The group consisted partially of similar and partially of new participants. Participants were again representatives of municipalities in the metropolitan region as well as of public transport providers. Furthermore, people with direct relation to the everyday life of immigrants participated to provide direct experience and impressions. These people were immigrants and voluntary integration workers. In focus group 3 ('validation of potential strategies'), eight representatives from municipalities, public transport, and voluntary workers participated. Again, partially new and known participants were selected.

The survey conducted between focus groups 2 and 3 served to evaluate the questions and topics of focus groups 1 and 2 more comprehensively. Therefore, the focus group topics were transferred into closed questions. Finally, 41 institutions, mainly municipalities, participated in the survey. Focus group participants were explicitly not invited to the survey. As can be seen in 
Table $1,76 \%$ of the respondents were from municipalities in the metropolitan region. Twelve percent were public transport providers. Voluntary organisations participated with a share of $10 \%$. Additionally, an institution of public interest that was not further defined participated. Fifty-six percent of the respondents indicated to have supportive measures to improve mobility of immigrants. Public transport providers added that they usually apply the measures that are offered by the superior transport association, which is the Rhine/Main Regional Transport Association in the metropolitan region. Table 1 summarises the characteristics of the survey among institutions.

Neither the focus groups nor the survey among institutions consists of a statistically significant sample. This must be clear when interpreting the results. However, the results are a valid indicator for hypotheses and creating a first picture of the current situation.

\subsubsection{Mobility provision and constraints}

In a first step of the analysis, the current situation in mobility provision for new immigrants was analysed. The focus groups as well as the survey showed that mobility support for immigrants is an important topic that concerns a number of actors. This is why a multitude of institutions decided to implement supporting measures. The majority of the participating institutions admitted that supporting measures for the mobility of immigrants were mainly introduced in 2015 with the sudden increase of immigrants all over Germany. Discussions and the survey made clear that municipalities were often unprepared and had to find quick solutions. In general, it became clear that, due to time pressure, districts often did not work together or jointly address the topic. Therefore, many isolated programmes and measures can be identified. However, it is clear that there exist a number of similarities as well as variety and differences, although they all belong to the same metropolitan region.

The discussions and the survey revealed that information provision is the most frequent measure to support immigrants after their arrival. Two steps can be identified: (1) Information material is provided and handed out to immigrants. The superior transport association, the Rhine/Main Regional Transport Association, has designed a brochure in German and Arabic that contains general information on the local public transport system. It explains how and where to buy tickets, how to read the schedules, or which tickets exist. The brochure works with a combined written and picture language. This brochure was mentioned as the most important material, as municipal transport operators mostly distribute this and similar brochures provided by the association. Participating municipal transport operators stated that they did not develop specific material. Material is often distributed during counselling hours, in shared accommodations, or at other contact points. (2) Information events, for instance in first accommodations, were conducted. These events were used to inform large groups of recently arrived refugees and provide them with relevant material. Whereas the brochure-based information is mostly focused on public transport, additional events and counselling hours often have a more general character, according to the results. The events contain information on public transport usage as well as the local options for further mobility, such as bicycles.

Integration workers, however, criticised that immigrants receive a huge amount of information with their arrival and first registrations. They start with a lot of paper and brochures that contain information that is necessary for their first months in the region. These include information on social offers, administrative duties, integration courses, and much more. Information is only one out of many. The workers, therefore, admit that information often gets lost, as recipients of information are overstrained. A stepwise and targeted provision of information would help to improve the probability that information is perceived. Municipalities and public transport organisations agreed with this criticism in the discussions. Yet, they emphasised that it is a question of financial resources and additional personnel, which is not available.

The provision of discounted or free public transport for refugees is uncommon. Thirteen percent of the surveyed practitioners indicated that they have a special ticket offer for refugees. The regional transport association, for instance, provides a mobility ticket for refugees in first accommodations that is valid for three months

Table 1 Characteristics of the survey among institutions

\begin{tabular}{lll}
\hline Type of institution & Number of survey participants (share in \%) & Number of institutions with mobility offers for immigrants (share in \%) \\
\hline Municipality & $31(76 \%)$ & $17(55 \%)$ \\
Public transport provider & $5(12 \%)$ & $3(60 \%)$ \\
Voluntary organisation & $4(10 \%)$ & $3(75 \%)$ \\
Institution of public interest & $1(2 \%)$ & $0(0 \%)$ \\
TOTAL & $41(100 \%)$ & $23(56 \%)$ \\
\hline
\end{tabular}

Source: Own sample 
and allows public transport usage in the respective district. Mostly, districts and their local transport operators rely on social tickets according to the German Social Security Code that is provided to people of social need. If the application for asylum is approved, refugees can also apply for this social ticket independently from the nation. Discussants emphasised that institutions, public transport operators, and municipalities underlie strong financial restrictions, which makes discounted or free tickets almost impossible to handle for many districts, as the cost gap has to be filled by these institutions. These tickets underlie a further constraint that creates difficulties for its users: These tickets are usually bound to a district or a federal state. As a metropolitan region with districts in three federal states, it strongly limits mobility, especially when it comes to the usage of further integration offers or language courses that often take place in another district.

Besides public transport, mobility by bicycle plays an important role among the supporting measures: (1) provision of bicycles and (2) bicycle courses. Regarding bicycle measures, institutions act diversely. Participants emphasised the importance of bicycles for daily mobility and as a relevant step towards integration. Bicycles enable flexible mobility and covering longer distances than on foot. They are also a relatively affordable mobility. Consequently, bicycle donations especially in 2015 made it possible to provide bicycles to immigrants. Fifty percent of the questioned municipalities stated that they provide bicycles for refugees. Different models were critically discussed and are applied: free bicycle provision, provision against voluntary labour, or provision against a deposit. Some municipalities and voluntary workers mentioned the experience that bicycles that are given away for free (i.e. as a present) are not valued. They said that bicycles were then often found abandoned in the closer environment. This experience was not confirmed by all municipalities. Due to the negative experience with free bicycles, some municipalities and the related organisations established models based on deposit or on voluntary work. Those who received a bicycle either gave a small amount of money or agreed to support local bicycle repair shops. The second solution is preferred, as it additionally has an integrating factor. Practitioners, furthermore, admitted that in the beginning severe traffic safety issues came up due to insufficient experience of immigrants with road transport in Germany. Therefore, some municipalities decided to make specific road traffic safety courses obligatory for those who want to have a bicycle from the public pool.

Furthermore, municipalities noticed that riding a bicycle is not common among this immigrant group. As a consequence, the demand for bicycles was rather low in the beginning. Therefore, respective courses have been set up. In particular, the traffic police and volunteer organisations offer courses for adults and children. Most women cannot ride the bicycle according to the experience of the course organisers. However, experience also showed that women are rather reserved towards these courses. Besides courses on how to ride a bicycle, volunteer workers offer bicycle tours for immigrants that help them to get to know the environment and where to be mobile by bicycle.

Car-related mobility does not receive attention from the mobility provision perspective. Cars are not relevant for early immigrant mobility. Furthermore, it is not a public duty to enable car mobility. However, some supportive measures are offered. For example, counselling programmes are offered if an immigrant wants to earn a driving licence. Even immigrants who have a driving licence from their home country usually cannot use the licence in Germany as there is no recognition agreement between most of the origin countries of refugees and Germany. Consequently, the driving licence can only be used for six months. After the expiration of the six months, the driving licences have to be transcribed, which requires a theoretical and practical driving test [36]. However, taking this test requires financial resources that usually do not exist in this group. A subsidy of the driving test is possible if the immigrant can prove that they will be employed for more than 12 months in a job that requires a driving licence. Two of the surveyed municipalities added that regular carpooling activities have been established. However, they are privately organised, not offered by institutions.

From a more general perspective, some of the surveyed municipalities and organisations criticised that they indeed make many offers for immigrants and do their best to communicate these offers, but the demand remains low. This covers bicycle courses as well as information events on mobility. Although this is not an issue shared by all practitioners, it seemed to be relevant, as it was deeply discussed. Discussion showed two causes for this problem: (1) information overload of the immigrants, as mentioned at the beginning of the chapter, and (2) cultural barriers that are difficult to overcome. The role of gatekeepers and multipliers was emphasised. The affected organisations admitted that it helps to work together with immigrants who already successfully use the local mobility offers, letting them spread the positive experience and improving the access to closed immigrant groups.

Furthermore, the participants of the focus groups and the survey admitted organisational problems that came up especially in 2015 and continued to be relevant in the following years. 2015 and 2016 were strong immigrant years. This affected municipalities and administrations from several directions: housing, administrative work, 
and integration courses. These duties already existed before and were carried out. However, the pressure of demand was many times higher, and administration was not prepared. Therefore, mobility could not be the centre of attention but had to be, as it is relevant for so many integrational measures. Herewith, practitioners mostly confirmed what has already been stated by research. Many cultural and language problems with mobility existed before but became evident with the large group facing these issues. Most surveyed organisations admitted that they do not have the financial resources or the personnel to provide the measures in the individualised or targeted way that would be necessary to be more effective. At the same time, discussions revealed that municipalities and other institutions of the metropolitan region cooperated little and mostly worked and implemented measures for mobility on their own. This is surprising, as mobility provision strongly benefits from joint implementation and programmes due to synergies and economies of scale. However, this is again a question of resources. Building cooperation requires time and personnel, which are not available.

Finally, some of the surveyed organisations mentioned decreasing acceptance of additional measures for immigrants. It was discussed that in 2015 and 2016 it was a lot easier to establish measures, such as bicycle donations, than it was in 2017. This can be explained by societal and political opinion. However, it must also be admitted that in 2017 the number of applications for asylum greatly decreased. Thus, public pressure was reduced, and attention was again brought to other topics. Daily business was back. Yet, municipalities stated that the need for supportive measures that help immigrants to be mobile still exists.

\subsubsection{Experience with immigrant mobility}

As a preparation for the development of the questionnaire for immigrants, a focus group was dedicated to experience with mobility behaviour. As the later questionnaire had to be very easy in language and understanding, this focus group allowed predefining the necessary questions and response options. However, it must be clear that this focus group contained assumption and hypotheses based on the personal experience of the participants. They gained their experience in their daily work with immigrants. Furthermore, immigrants who were already in good command of the German language enriched the focus group. The later survey among immigrants gave a quantitative indication of the mobility behaviour.

The analysis of the discussions in this focus group indicated that immigrants tend to move in their direct environment and avoid longer distances. The reasons that are named are cost and uncertainty in the usage of public transport. Especially in the peripheral areas of the metropolitan region, the discussants emphasised the importance of walking and bicycling. The experts explained that the modal choice strongly varied according the trip purpose. Administrative appointments or integration courses that are often farther away are reached by public transport independently from the location of the accommodation. However, the experts mentioned that the more rural immigrants are accommodated, the less they rely on public transport for other trip purposes, such as daily shopping or social activities. The experts indicated that the more rural the environment the immigrants live in, the more they tend to master their social life in the direct surrounding. Immigrants in urban accommodations, in turn, were significantly more mobile and willing to leave their quarter for social activities. According to the experts, coverage with and frequency of public transport strongly influence this behaviour.

Again, it was emphasised that riding a bicycle cannot be assumed as a common ability among the majority of immigrants from the Middle East or Africa. It was assumed that especially women have reservation towards this mode of transport, although it is essential for being mobile, specifically in areas that are more rural. Car mobility was assessed as irrelevant. However, experts assumed that in a later period of the immigrants' settlement this could change, as a car has a strong symbolic character. However, financial and organisational restrictions make it unimportant in the early stage.

\subsection{Mobility behaviour of recently settled immigrants 4.2.1 Sample description}

Similar to the data collection among institutions, this survey is not statistically significant (see section 4.1.1). Yet, the results give an important indication on mobility behaviour of immigrants, helps to overcome discussions on individual impressions and shows an approach for addressing immigrants with scientific surveys. Table 2 summarises the sample and compares the sample characteristics to official statistics. In total, 96 immigrants completed the survey. Of these, $65 \%$ were male, and 35\% were female. In 2017, $60.5 \%$ of the applicants for asylum in Germany were male and $39.5 \%$ were female [37]. In $2016,65.7 \%$ of the applicants were male and $34.3 \%$ were female [38]. This makes this sample realistic in terms of gender.

Forty-six percent of the respondents were between 18 and 30 years old; $27 \%$ were between 31 and 45 years old; $16 \%$ were between 46 and 60 years old; and only $7 \%$ were under 17 and $4 \%$ over 60 years old. Official statistics of the respective ministry show a slightly different age distribution (taking into account that the statistics use ranges differing by one year compared to our sample; see Table 2): $5.9 \%$ of the applicants were between 16 
Table $\mathbf{2}$ Characteristics of the sample in comparison to official statistics

\begin{tabular}{|c|c|c|c|}
\hline Category & Sample share & Official statistics 2016 & Official statistics 2017 \\
\hline \multicolumn{4}{|l|}{ Gender } \\
\hline Male & $65 \%$ & $65.7 \%$ & $60.5 \%$ \\
\hline Female & $34 \%$ & $34.3 \%$ & $39.5 \%$ \\
\hline Age & & $30.3 \%(<16)$ & $39.4 \%(<16)$ \\
\hline$<17$ & $7 \%$ & $5.9 \%(16-18)$ & $5.6 \%(16-18)$ \\
\hline $18-30$ & $46 \%$ & $37.6 \%(18-29)$ & $30.3 \%(18-29)$ \\
\hline $31-45$ & $27 \%$ & $19.8 \%(30-44)$ & $18.4 \%(30-44)$ \\
\hline $46-60$ & $16 \%$ & $5.2 \%(45-59)$ & $5 \%(45-59)$ \\
\hline$>60$ & $4 \%$ & $1.2 \%(>59)$ & $1.3 \%(>59)$ \\
\hline \multicolumn{4}{|l|}{ Origin } \\
\hline Middle East & $70 \%$ & N.A. & N.A. \\
\hline Eastern Africa & $21 \%$ & N.A. & N.A. \\
\hline Northern Africa & $2 \%$ & N.A. & N.A. \\
\hline Missing Value & $7 \%$ & & \\
\hline Year of arrival & & \multicolumn{2}{|c|}{ Change in first-instance applications for asylum } \\
\hline Before 2015 & $22 \%$ & \multicolumn{2}{|l|}{$+57.9 \%(2013 / 2014)$} \\
\hline 2015 & $42 \%$ & \multicolumn{2}{|l|}{$+155.3 \%(2014 / 2015)$} \\
\hline 2016 & $24 \%$ & \multicolumn{2}{|l|}{$+63.5 \%(2015 / 2016)$} \\
\hline 2017 & $6 \%$ & \multicolumn{2}{|l|}{$-72.5 \%(2016 / 2017)$} \\
\hline Missing Values & $6 \%$ & & \\
\hline
\end{tabular}

Source: Own sample and [37, 38, 41]

and 18 years old (5.6\% in 2017); $1.2 \%$ of asylum seekers were older than 60 years (1.7\% in 2017); $37.6 \%$ of applicants in 2016 were between 18 and 30 years old (30.3\% in 2017); and $19.8 \%$ were between 31 and 45 years old (18.4\% in 2017) [37, 38]. Data show that the age group of $18-30$ years is overrepresented, as well as the group between 31 and 45 . However, this can be easily explained: The official statistics have access to the full population of asylum seekers, whereas children were not considered for this survey. Therefore, the group of under-17-year-old respondents is significantly lower than in reality. This, however, does not negatively influence the validity of the sample, as the mobility behaviour of children is strongly influenced by parents or other adults in their environment.

The majority of the sample (70\%) comes from the Middle East, and 23\% of the respondents come from an African country. These proportions also reflect the fact that Syria has become the most common country of origin of asylum seekers, especially since 2015 . Still, $7 \%$ did not answer the question about the country of origin or gave misleading answers. This again emphasises the difficulty with socio-demographic questions in this group. Furthermore, $42 \%$ of the respondents arrived in Germany in 2015, which was the strongest immigration year in Germany. Another 26\% arrived in 2016, 22\% before 2015 , and only $6 \%$ in 2017. Six percent did not answer the question. In Table 2, the years of arrival are contrasted to the official statistics on first-instance applications for asylum. The official statistics show that from 2014 to 2015 the highest increase with a plus of $155 \%$ appeared. Especially instable political situations in the Middle East but also drought and poor living conditions in Africa made people leave their country of origin and come to Europe. From 2016 to 2017, a decrease of 72\% can be registered. A reason could be stricter migration policies in several countries.

\subsubsection{Short-distance mobility from an immigrant perspective}

Data indicate a strong difference in mobility behaviour between men and women. Data show that around one third of the respondents possess a driving licence in their country of origin. However, driving licences are most common among men. Nevertheless, only seven of the survey respondents are allowed to use the driving licence in Germany. Seventy-three percent of the respondents remarked that they would like to take the test but simply cannot afford it or even afford a car at a later stage. Consequently, it is not surprising that a car does not play any role in the daily modal split. Ninety-eight percent of the respondents indicated that they never or almost never use a car as a driver. However, at least $16 \%$ of the respondents stated that a few times per month they are car passenger. Ten percent even indicated that 
they are a car passenger every week. This statement is also confirmed by the focus group results. Here, it was stated that many integration workers often take the immigrants with them or even bring them to important destinations. The results also show that a taxi is irrelevant. It can be assumed that it exceeds the immigrants' budget.

If a car is irrelevant for immigrants, other modes of transport (not car-based) must gain importance. Public transport is, therefore, an important mode of transport. However, differences can be noticed depending on the location of the accommodation. The more peripherally the accommodation is located, the less the respondents used public transport. Data indicate that $67 \%$ of the respondents in central areas use public transport on a daily basis, whereas only $40 \%$ have the same frequency in peripheral areas. Still, 50\% use public transport weekly despite living in a peripheral area. Figure 2 compares the differences in the frequency of public transport usage between peripheral and central areas. A reason for these differences can be that in peripheral areas the next bus or train station is between a 10- and 20-min walk away, whereas in central areas, $75 \%$ of the respondents indicated a maximum distance of $5 \mathrm{~min}$. These problems are not immigrant-specific but show a general problem of public transport in peripheral areas. It can be expected that this problem increases the more peripherally one lives.

Those respondents with a high usage frequency indicated that public transport is flexible and relatively cheap. Fifty percent of the immigrants that never or rarely use public transport indicated that tickets are too expensive. Respondents here generate a contradiction. Whereas some stated that public transport is an affordable mode of transport, others stated the opposite. A specific characteristic of this region must be understood at this point. As the region consists of several districts, depending on the origin and destination, regional borders have to be crossed. Sometimes this leads the public transport user into a new tariff zone, although they have taken only one or two stations. This can disproportionally increase prices. Additionally, respondents indicated language barriers when trying to use public transport. Understanding the ticket machine, the timetable, or selecting the correct ticket are named as the most important difficulties. The confusion about the correct ticket is also reflected in the tickets that are purchased: $47 \%$ regularly purchase a monthly ticket, and $56 \%$ regularly use single tickets (which are relatively expensive when regularly using public transport). The possibility of a free ticket is rarely taken. Immigrants mostly stated that they were not aware of this possibility (only 23\% knew this possibility).

Public transport is mostly used for reaching more distant destinations that are too far away for walking. Fifty-six percent use public transport to attend integration courses or for doing their daily shopping. Public transport is also important for reaching official authorities or going to the doctor (each 55\%). In case of leisure, public transport loses relevance. Only $35 \%$ indicated that they use public transport. It can be assumed that leisure rather takes place in the immediate environment. Also, religious sites are less relevant (only $31 \%$ ).

A bicycle is another relevant mode of transport. Around $20 \%$ of the respondents indicated that they are able to ride a bike. A gender difference is obvious: Mostly men can ride a bike. Almost no women are able to do so. Still, data show that the bicycle significantly gains importance in peripheral areas. Figure 3 summarises the results on the frequency of bicycle usage in central and peripheral areas. Fifty percent of peripherally accommodated respondents use a bicycle every day and $23 \%$ every week. In central areas, only $9 \%$ use one every day and $20 \%$ every week; $63 \%$ of the participants in central areas stated that they never or almost never use a bicycle. Bringing these results together with the usage of public transport, it can be interpreted that immigrants bridge their problems with public transport by taking a bicycle. However, as women have significantly less ability in riding bicycles this group has to live with reduced mobility. Among those who only rarely or never use a bicycle, the reasons are usually that they either cannot ride a bicycle or they do not have one. When being asked whether they were aware of the possibility of bicycle courses, $17 \%$ stated that they knew the courses and $6 \%$ said they already had taken a course. Among those immigrants who said they regularly used a bicycle,

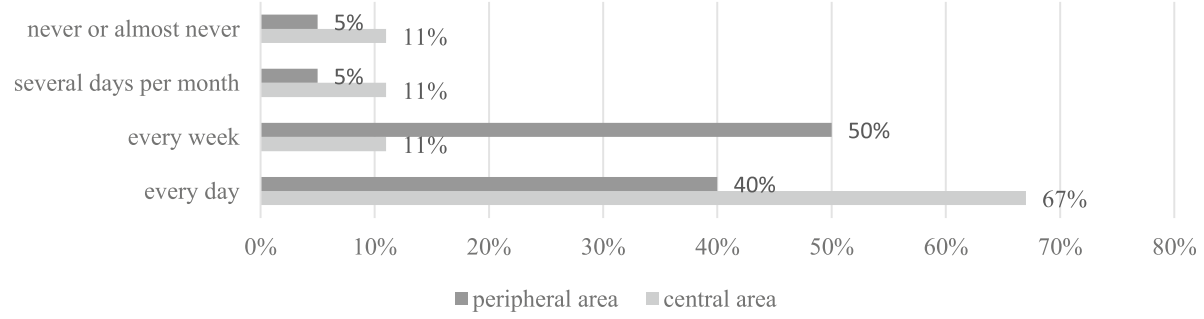

Fig. 2 Frequency of public transport usage according to location of the accommodation. Source: Own sample 


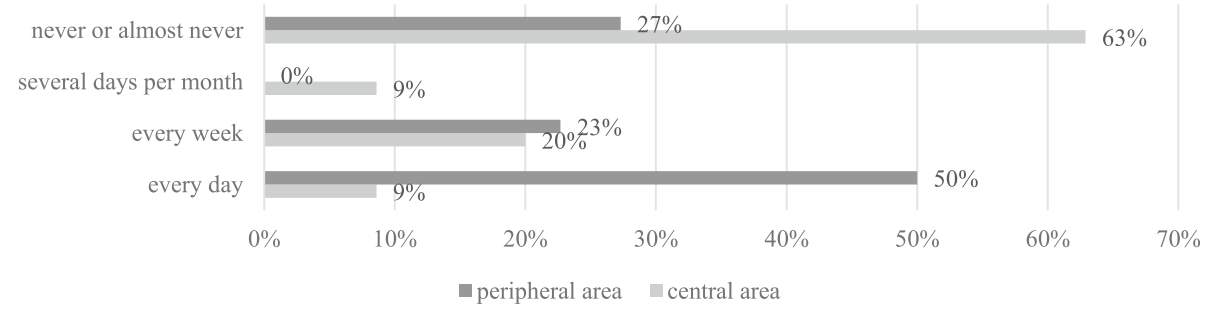

Fig. 3 Frequency of bicycle usage according to location of the accommodation. Source: Own sample

bicycle repair shops were known. Nevertheless, only few take the possibility of these shops (getting the bicycle repaired or work in the shop).

In contrast to public transport, bicycles are often used for leisure activities but also for local shopping. They are less relevant for official appointments.

Finally, walking also plays an important role in the daily short-distance mobility behaviour. Women especially expressed discomfort and uncertainty in the context of public transport and bicycles. For instance, they stated they were afraid of missing the bus station and getting lost. In general, it became clear that women were significantly less confident in moving around. As a consequence, walking is seen as an important way of movement. The focus groups additionally revealed that women sometimes even prefer to walk longer distances than to take a bus since they feel uncomfortable or uncertain. In general, $56 \%$ of the respondents stated that they walk several times per day for being mobile, and $20 \%$ indicated that they walk several times a week. The most typical purposes are local shopping and leisure.

From research, it is known that modal choice is determined by the attractiveness of the offers. The sole existence of offers is not the only decisive factor. It is also relevant whether the potential users are informed. The previous analysis has shown that there is a variety of offers. However, municipalities often complain that these offers are not used. Data revealed that especially those immigrants with a relatively short length of stay are rather badly informed and are often unaware of the possibilities. Only $23 \%$ of the respondents, for instance, were aware that they can apply for discounted public transport tickets according to the German Social Security Code as valid for people with the need of social support. However, the cost for these tickets varies between cities. There are no standardised rules for these so-called social tickets, and municipalities can freely decide whether to offer such a ticket. In Frankfurt, for instance, the so-called Frankfurt pass, which is the discounted ticket, currently costs around 63 EUR as a monthly ticket (regular 89 EUR) [39]. Similar prices can be found in other cities of the metropolitan region. As these prices are still relatively high and due to language barriers, it is possible that immigrants do not understand that they receive a discounted price.

Many cities, municipalities, and organisations also offer bicycle courses. Here, participants can learn how to ride a bicycle and how to safely move on the road. Only $17 \%$ of the respondents knew that such offers exist, and only $6 \%$ made use of the offer. It is remarkable that especially those immigrants who cannot ride a bicycle are unaware of these offers. However, the courses should be of interest for this group of immigrants. Therefore, it is specifically necessary to address these people. Logically, most of the respondents also did not know about bicycle repair shops, where they have the opportunity to get their bicycles repaired for low prices or learn how to repair their bicycle on their own. Likewise, informative brochures are not commonly known among the respondents. However, these brochures are important, as they exist in many different languages and provide information on mobility and transport in the region in an understandable way. Still, these offers require that the target group can read, but this is often not the case. Therefore, these brochures pass by the immigrants without being appreciated. Some respondents stated that they know these brochures but declared that they do not need the contained information to be adequately mobile.

\section{Interpretation and recommendations}

Data of this paper were collected in three steps: (1) focus groups, (2) survey among institutions developed from the focus groups, and (3) survey among immigrants from the Middle East and Africa. From these steps, conclusions on the mobility behaviour of immigrants can be drawn. These insights help evaluating the effectiveness of measures by municipalities, public administration, or public transport organisations to support immigrant mobility. Contrasting the experience of the mobility supply side with the demand side reveals which measures already work well and have a supporting effect and where strategies are needed to meet the mobility needs of this immigrant group.

Generally, the results revealed that immigrants have different mobility behaviour and do not rely on car mobility. This confirms the results of previous research that 
emphasised the importance of public transport and walking. Although the research sample was relatively small, carpooling appears as a relevant mobility option, as already pointed out by previous studies (e.g. [21]). Results also showed that municipalities have a strong interest in immigrants being mobile. They need immigrants to be mobile and able to move around to improve the integration process. Again, research is confirmed $[2,3]$.

\subsection{Barriers to mobility from an immigrant perspective}

Analysis has shown a long list of barriers that limit immigrants' mobility: Language barriers make it difficult to understand information. Different mobility routines and cultures impede immigrants from directly using local transport systems since they cannot ride a bicycle or the ticket system is different in their country of origin, for example. Sometimes gender represents a barrier when culture impedes men and women from participating in joint courses. Analysis revealed that immigrants often do not have the necessary information on tickets or local bus systems since the immigrants did not understand it or were unable to filter the necessary information. The reason was not that municipalities did not provide information. Data have shown that immigrants suffer from information overload and uncertainty in handling local mobility. Efforts of public administrations and transport planners are immense, such as traffic safety courses, information events, and multilingual offers. Yet, uncertainty and reservations towards mobility remain. Strategies are needed to reduce the plethora of information and instead transfer or provide information that is targeted and understandable for the target group. A stronger activation of immigrants to participate in courses and to overcome scepticism and fear is needed. Experience and knowledge can reduce uncertainty.

\subsection{Synergy creation between immigrant and non- immigrant mobility}

However, results emphasised that resources for additional offers are limited, and besides immigrants, non-immigrants suffer from limited mobility. Many problems that appear for immigrants can be transferred to non-immigrants as well. Mobility in rural areas, for example, is a relevant topic for all. The dependency on cars is an issue for all who cannot drive, including people without a driving licence or without car, children, or the elderly. If additional offers are provided only for immigrants, social dissonance can be caused. This means that although nationality and immigration background are strong criteria that affect mobility behaviour, it is important to find additional criteria that can reveal similarities and lead to new user groups. Joint offers, such as traffic safety and bicycling courses for children of all nationalities and bicycle tours for immigrants and non-immigrants, bring a number of advantages: social integration, improved offers for all, and efficient use of public resources.

Results have shown not only potential for improvements in the provision of mobility but also a need for action in the organisation of mobility for immigrants. Discussions revealed that there is a plethora of initiatives of municipalities or transport operators. However, with the increase in applications for asylum in 2015, measures had to be rapidly intensified. This ad hoc planning led to rather decentralised organisation and measure development. Municipalities, public transport operators, and other actors that were confronted with a need for action were developed. The data analysis revealed that implementing organisations often feel overloaded, arguing that neither their structures nor their competencies are designed for these tasks. It was revealed that there are no indications or guidelines for municipalities on how to support immigrant mobility and how to structure the work. Voluntary organisations additionally complement the process of support for immigrant mobility (e.g. with information offers, carpooling activities). However, work between the several actors is often uncoordinated or unstructured. Work and measures are set up ad hoc and all based on conscience. Overload of voluntary work and municipalities has to be reduced. Guidelines, structures, and organisation recommendations could help.

\subsection{Fostering cooperation between institutions}

Against this background, cooperation becomes an important topic. It was shown that actors mostly act on their own. There is little cooperation or exchange of experience. Some municipalities established round tables that bring together local actors to exchange information. However, little city boundary-crossing cooperation can be found. Experience exchange often ends at the city boundaries. The same can be found for many supportive measures: Actors rarely cooperate and often implement measures on their own, although the whole region faces similar challenges. At the same time, actors stated not to have enough resources to address specific mobility needs. Structures are needed for municipalities to exchange experience and cooperate more easily in mobility provision. Cooperation structures must reflect the fact that mobility crosses city boundaries, and immigrants must be able to cross districts.

Finally, it is known from research that the geographical location can have a strong impact on mobility behaviour. In peripheral regions, distances even for daily mobility are usually longer, public transport is less frequented, and cars often gain importance. The metropolitan region of Frankfurt Rhine-Main is characterised by diverse spatial structures. There are highly agglomerated areas, such as Frankfurt or Wiesbaden. At the same 


\section{Appendix}

Table 3 Strategies for improving mobility of immigrants

\begin{tabular}{|c|c|c|}
\hline Strategic goal & Implementation measures & Addressed actors \\
\hline Reducing mobility barriers & $\begin{array}{l}\text { 1. Incentivising participation in courses, e.g. with bonus point systems } \\
\text { 2. Information centres on mobility options } \\
\text { 3. Integrate information on mobility in language and integration } \\
\text { courses } \\
\text { 4. Improving information flow, e.g. clear information processing, } \\
\text { development of templates for graphical presentation of information, } \\
\text { smartphone applications } \\
\text { 5. Reducing fear of public transport, e.g. optimising signage, mobility } \\
\text { learning groups, and mobility guides }\end{array}$ & $\begin{array}{l}\text { Learning mobility: } \\
\text { Organisers of integration courses, voluntary } \\
\text { workers, or traffic associations } \\
\text { Information provision: } \\
\text { Transport association and operators, cities, and } \\
\text { municipalities }\end{array}$ \\
\hline $\begin{array}{l}\text { Using synergies between } \\
\text { user groups }\end{array}$ & $\begin{array}{l}\text { 1. Identifying similarities with other traveller groups } \\
\text { 2. Developing mobility offers for immigrants and non-immigrants }\end{array}$ & Politics and science \\
\hline $\begin{array}{l}\text { Building organisational } \\
\text { structures }\end{array}$ & $\begin{array}{l}\text { 1. Development of templates for clear and readable information } \\
\text { provision adapted to the target group } \\
\text { 2. Gaining patronages and drivers for improved mobility offers, e.g. } \\
\text { regional politics } \\
\text { 3. Defining responsibilities, providing contacts that help implementing } \\
\text { organisations } \\
\text { 4. Strengthening voluntary work as a pillar of integration }\end{array}$ & $\begin{array}{l}\text { Regional and local politics and responsible } \\
\text { persons for strategic transportation political } \\
\text { decisions }\end{array}$ \\
\hline $\begin{array}{l}\text { Strengthening } \\
\text { cooperation }\end{array}$ & $\begin{array}{l}\text { 1. Including immigrants in the exchange of experience } \\
\text { 2. Strengthening networks } \\
\text { 3. Synchronising round tables and similar platforms } \\
\text { 4. Developing communication platforms, e.g. between politics, } \\
\text { municipalities, and voluntary workers }\end{array}$ & $\begin{array}{l}\text { Local responsible persons as patronages, e.g. } \\
\text { mayors }\end{array}$ \\
\hline $\begin{array}{l}\text { Aligning mobility, } \\
\text { geographical location, } \\
\text { and housing }\end{array}$ & $\begin{array}{l}\text { 1. Assessing the potential of institutionalised rides or carpooling, } \\
\text { bikesharing systems in peripheral areas } \\
\text { 2. Creating safety for all participants } \\
\text { 3. Assessing the potential for demand-based services, taking into ac- } \\
\text { count different mobility conditions. } \\
\text { 4. Mobility points to improved mobility in peripheral areas } \\
\text { 5. Assessing new demand potentials }\end{array}$ & $\begin{array}{l}\text { Federal transport policy, science, funding } \\
\text { bodies for public investments, municipalities }\end{array}$ \\
\hline
\end{tabular}

time, there are peripheral districts and municipalities. Immigrants are mostly accommodated in rather peripheral regions, as there was enough space to establish first accommodations. However, data showed that especially in peripheral regions immigrants have mobility barriers and are less mobile, as also confirmed by research. This raises a planning dilemma: Housing in peripheral areas is significantly cheaper than in city centres, which makes it more attractive to house immigrants in peripheral areas. However, mobility is limited. As a consequence, integration can be disturbed. The challenge is to find strategies to plan mobility and housing in integrated concepts. This not only helps immigrants but generates synergies for all.

\subsection{Strategies for improving the mobility of immigrants}

The need for action covers more than just mobility demand. Actions are also needed in the whole mobility chain: organisation, cooperation, and provision. Solving these issues, therefore, means integrating demand and supply, bringing together the necessary actors, and providing solutions for municipalities and organisers.

Bringing together these results, strategies can be derived to improve mobility organisation and provision. These strategies are directed to transport and city planners, transport politics, voluntary organisations, or public administration. The strategies were validated in a focus group. The findings came with five strategic goals. They give indication as to how immigrant mobility can be improved on the demand and supply sides. For each strategic goal, implementation measures can be identified. They are not claimed to be complete but were rated as specifically important for improvements in immigrant mobility provision. Strategic goals can be (1) reducing mobility barriers, (2) using synergies between different mobility user groups, (3) building organisational structures that facilitate the work of municipalities and voluntary workers, (4) strengthening cooperation between crossing city boundaries, and (5) aligning mobility planning with the geographical location and accommodation to impede enclaves or immobility. The strategies show that there is potential for improvement for the supply and organisation of immigrant mobility but also show that approaches are needed to facilitate the access to mobility. Smartphones and digital media can play an important role as they allow individually reaching the immigrants and communicating demand-based and targeted information, for instance with a smartphone application. Previous research has already shown the central role of smartphones in immigrants' life. The 
smartphone is their connection to families and friends and an important source of information even if they have only poor language skills. Often, they already bring a cheap mobile phone from their country of origin [40].

A detailed overview of the strategies can be seen in Appendix: Table 3.

\section{Conclusion}

Immigrant mobility is a complex topic that requires attention. The analysis has shown that it is important not just for immigrants to be mobile but also that public administration must have an intrinsic interest to enable recently settled immigrants to be mobile and adapt to the local mobility system. Based on data collected in a research project on short-distance mobility of refugees in the metropolitan region of Frankfurt Rhine-Main, mobility needs of refugees in the region were analysed and their barriers were identified. Language and different mobility cultures make it difficult for many immigrants to directly adapt to the local mobility system. It was shown that already today there are many measures to support immigrants in their mobility. However, immigrants are often unaware of their options. This can be explained by information overload. Immigrants often cannot filter the right information. As a consequence, it often appears as if they had never received information. At the same time, municipalities claim that they often do not have enough resources to intensify supportive measures. Results showed that implementing organisations, such as municipalities or transport operators, are often left to their own. There is little help or organisational structure that relieves resources, administration, and voluntary organisations. The analysis showed that there are many public efforts that often do not solve the barriers on the demand side and supply side. Therefore, five strategies were developed that, when implemented, help to meet immigrants' mobility needs better but also the needs of municipalities and transport operators.

Although the samples in the present paper are statistically not significant, the results give an important indicator for further research, which then requires additional funding. Further research should try to conduct surveys in the immigrants' languages to reduce the risk of misunderstandings. Furthermore, this can help to increase the sample size. Working with the native languages can also help ask more complex and detailed questions on mobility behaviour. This paper is an initial research that not only presents indications on mobility behaviour and mobility offers, but also provides important insights and experience for later research on how to handle such a complex topic driven by cultural differences and language barriers.

The paper thus contributes to a deeper understanding of what the mobility needs of recently settled immigrants from the Middle East and Africa are and how supportive measures from public organisations can help. With strategic goals and the suggested implementation measures, policy makers and public administration receive a guideline for how to improve organisation and planning of mobility supporting measures to their own advantage, since resources can be used more effectively and to the immigrants' advantage as their needs are met.

\section{Acknowledgements \\ Not applicable.}

\section{Funding}

The data used here were collected as part of the research project 'Shortdistance mobility of new immigrants as part of a successful integration strategy: A needs analysis for the Rhine-Main area'. The project (project number: 535/17-17) was funded by the State of Hesse and the HOLM-funding programme 'Innovations in the Field of Logistics and Mobility' of the Hessian Ministry of Economic Affairs, Energy, Transport and Regional Development. The funding body had not influence on the design of the study, collection, analysis and interpretation of data and in writing the manuscript.

\section{Availability of data and materials}

The datasets analysed during the current study are not publicly available due to privacy reason. The data sets contain personal data that may not be publicly available. It was assured that data generated for the research project are only used for this research context.

\section{Author's contribution}

The author wrote, read and approved the final manuscript.

\section{Authors' information}

Isabella Geis is a doctoral candidate at the Chair for Mobility, Trade and Logistics at Zeppelin University, Germany. She now works as a Senior Consultant for Q_PERIOR. During the research and work for this manuscript, she worked as a researcher at the Centre for Logistics and Mobility of the Fraunhofer-Institute for Material Flow and Logistics in Frankfurt/Main, Germany. Her overall research interests are transportation research, intelligent transportation systems and transportation policy and mobility behaviour. She has presented her several papers at German and international conferences, such as at the ITS World/European Congresses, the Annual Meeting of the Midwest Political Science Association or at the Annual Meeting of the Transportation Research Board. Her work has been published at the IET Intelligent Transportation Systems and the Transportation Research Record: Journal of the Transportation Research Board.

\section{Competing interests}

The author declares that he/she has no competing interests.

\section{Publisher's Note}

Springer Nature remains neutral with regard to jurisdictional claims in published maps and institutional affiliations.

Received: 27 October 2018 Accepted: 16 April 2019

Published online: 08 May 2019

\section{References}

1. Jeekel, J. F., \& Martens, C. J. C. M. (2017). Equity in transport: Learning from the policy domains of housing, health care and education. European Transport Research Review, 9(4), 53. https://doi.org/10.1007/ s12544-017-0269-1.

2. Li, S., \& Zhao, P. (2017). Restrained mobility in a high-accessible and migrant-rich area in downtown Beijing. European Transport Research Review, 10(1), 4. https://doi.org/10.1007/s12544-017-0278-0.

3. Boisjoly, G., \& Yengoh, G. T. (2017). Opening the door to social equity: Local and participatory approaches to transportation planning in Montreal. 
European Transport Research Review, 9(3), 43. https://doi.org/10.1007/s12544017-0258-4.

4. European Commission (2017) EU transport in figures: Statistical pocketbook 2017.

5. Geis, I., \& Schulz, W. H. (2016). Incentivizing modal change - exploring the effect of multimodal information and ticketing systems for medium and long distances in Europe. Transportation Research Record: Journal of the Transportation Research Board, 2565, 1-7. https://doi.org/10.3141/2565-01.

6. Eriksson, L., Garvill, J., \& Nordlund, A. M. (2008). Interrupting habitual car use: The importance of car habit strength and moral motivation for personal car use reduction. Transportation Research Part F: Traffic Psychology and Behaviour, 11(1), 10-23. https://doi.org/10.1016/j.trf.2007.05.004.

7. Diana, M., \& Mokhtarian, P. L. (2009). Desire to change one's multimodality and its relationship to the use of different transport means. Transportation Research Part F: Traffic Psychology and Behaviour, 12(2), 107-119. https://doi. org/10.1016/j.trf.2008.09.001.

8. Schwanen, T., Lucas, K., Akyelken, N., et al. (2015). Rethinking the links between social exclusion and transport disadvantage through the lens of social capital. Transportation Research Part A: Policy and Practice, 74, 123-135. https://doi.org/10.1016/j.tra.2015.02.012.

9. Hessische Landesregierung (2017) Zahlen \& Fakten. https://fluechtlinge. hessen.de/flucht-asyl/zahlen-fakten. Accessed 8 Aug 2017.

10. McGuckin, N., \& Murakami, E. (1999). Examining trip-chaining behavior: Comparison of travel by men and women. Transportation Research Record: Journal of the Transportation Research Board, 1693, 79-85. https://doi.org/10. $3141 / 1693-12$

11. Fu, X., \& Juan, Z. (2017). Exploring the psychosocial factors associated with public transportation usage and examining the "gendered" difference. Transportation Research Part A: Policy and Practice, 103, 70-82. https://doi. org/10.1016/j.tra.2017.05.017

12. Frändberg, L., \& Vilhelmson, B. (2011). More or less travel: Personal mobility trends in the Swedish population focusing gender and cohort. Special section on Alternative Travel futures, 19(6), 1235-1244. https://doi.org/10. 1016/j.jtrangeo.2011.06.004

13. Gefen, D., \& Straub, D. W. (1997). Gender differences in the perception and use of e-mail: aneExtension to the technology acceptance model. MIS Quarterly, 21(4), 389-400. https://doi.org/10.2307/249720.

14. Buehler, R. (2011). Determinants of transport mode choice: A comparison of Germany and the USA. Journal of Transport Geography, 19(4), 644-657.

15. Blumenberg, E. (2009). Moving in and moving around: Immigrants, travel behavior, and implications for transport policy. Transportation Letters, 1(2), 169-180. https://doi.org/10.3328/TL.2009.01.02.169-180.

16. Tal, G., \& Handy, S. (2010). Travel behavior of immigrants: An analysis of the 2001 National Household Transportation Survey. Transport Policy, 17(2), 8593. https://doi.org/10.1016/.jtranpol.2009.11.003.

17. $\mathrm{Hu}, \mathrm{L}$. (2017). Changing travel behavior of Asian immigrants in the U.S. Transportation Research Part A: Policy and Practice, 106, 248-260. https://doi. org/10.1016/j.tra.2017.09.019.

18. Yu, S. (2016). "I am like a deaf, dumb and blind person": Mobility and immobility of Chinese (im) migrants in Flushing, Queens, New York City. Journal of Transport Geography, 54, 10-21. https://doi.org/10.1016/j.jtrangeo. 2016.05.004.

19. Bose, P. S. (2014). Refugees in Vermont: Mobility and acculturation in a new immigrant destination. Journal of Transport Geography, 36, 151-159. https:// doi.org/10.1016/j.jtrangeo.2014.03.016.

20. Handy, S., Blumenberg, E., Donahue, M., et al. (2011). Travel behavior of Mexican and other immigrant groups in California. Berkeley Planning Journal, 21(1), 2-24.

21. Blumenberg, E., \& Smart, M. (2014). Brother can you spare a ride? Carpooling in immigrant neighbourhoods. Urban Studies, 51(9), 1871-1890. https://doi.org/10.1177/0042098013502825.

22. Smart, M. J. (2015). A nationwide look at the immigrant neighborhood effect on travel mode choice. Transportation, 42(1), 189-209. https://doi.org/ 10.1007/s11116-014-9543-4.

23. Tsang, F., \& Rohr, C. (2011). Impact of migration on transport and congestion. Santa Monica, California, US: Rand Corporation.

24. Harms, L. (2007). Mobilität ethnischer Minderheiten in den Stadtgebieten der Niederlande. Deutsche Zeitschrift für Kommunalwissenschaften (DfK), 46(2), 78-94.
25. Welsch, J., Conrad, K., \& Wittowsky, D. (2018). Exploring immigrants travel behaviour: Empirical findings from Offenbach am Main, Germany. Transportation, 45(3), 733-750. https://doi.org/10.1007/s11116-016-9748-9.

26. Regionalverband FrankfurtRheinMain (2018) Die Region FrankfurtRheinMain in Zahlen und Fakten. https://www.region-frankfurt.de/Regionalverband/ Region-in-Zahlen\#a2. Accessed 10 Oct 2018.

27. Immowelt.de (2018) Immobilienpreise ermitteln. https://www.immowelt.de/ immobilienpreise/index.aspx. Accessed 13 Jan 2019.

28. Regionalverband FrankfurtRheinMain (2018) Statistik Viewer Metropolregion http://ftp.planungsverband.de/ia/metropolregion/bevoelkerung/atlas.html. Accessed 13 Oct 2018.

29. Airports Council International (2018) ACl Europe Air Traffic Report 2017.

30. Wohnungsbörse (2018) Aktuelle Mietspiegeldaten in Deutschland. https:// www.wohnungsboerse.net/mietspiegel-mietpreise. Accessed 13 Jan 2019.

31. Empirica (2018) Städte mit den höchsten Mietpreisen für Wohnungen in Deutschland im 3. Quartal 2018. https://de.statista.com/statistik/daten/ studie/1885/umfrage/mietpreise-in-den-groessten-staedten-deutschlands/. Accessed 15 Oct 2018

32. Luttik, J. (2000). The value of trees, water and open space as reflected by house prices in the Netherlands. Landscape and Urban Planning, 48(3), 161167. https://doi.org/10.1016/S0169-2046(00)00039-6.

33. TU Dresden. (2015). Sonderauswertung zum Forschungsprojekt "Mobilität in Städten - SrV 2013". Drseden: Städtevergleich.

34. Oakil, A. T. M., Manting, D., \& Nijland, H. (2016). Determinants of car ownership among young households in the Netherlands: The role of urbanisation and demographic and economic characteristics. Journal of Transport Geography, 51, 229-235. https:/doi.org/10.1016/j.jtrangeo.2016.01.010

35. Geis, I. (2017) Ergebnisbericht: Nahmobilität für Migranten als Bestandteil einer erfolgreichen Integrationsstrategie - Eine Bedarfsanalyse für das RheinMain-Gebiet, Frankfurt a.M.

36. ADAC (2017) Führerscheinumtausch und -erwerb bei Flüchtlingen aus Syrien

37. Bundesamt für Migration und Flüchtlinge (2018) Das Bundesamt in Zahlen 2017 - Asyl, Migration und Integration.

38. Bundesamt für Migration und Flüchtlinge (2017) Aktuelle Zahlen zu Asyl.

39. Verkehrsgesellschaft Frankfurt (2016) Fahrkarten zum Frankfurt-Pass. https://www. vgf-ffm.de/en/fares-tickets-and-timetables/tickets/frankfurt-pass/. Accessed 14 Oct 2018.

40. Kaufmann, K. (2018). Navigating a new life: Syrian refugees and their smartphones in Vienna. Information, Communication \& Society, 21(6), 882898. https://doi.org/10.1080/1369118X.2018.1437205.

41. Bundesamt für Migration und Flüchtlinge (2016) Das Bundesamt in Zahlen 2015 - Asyl, Migration und Integration.

\section{Submit your manuscript to a SpringerOpen ${ }^{\circ}$ journal and benefit from:}

- Convenient online submission

- Rigorous peer review

- Open access: articles freely available online

- High visibility within the field

- Retaining the copyright to your article

Submit your next manuscript at $\boldsymbol{\nabla}$ springeropen.com 